\title{
To go or not to go: The relationship between commuting and withdrawal behavior
}

\author{
Onur Emre \\ Yalova University, Turkey \\ Email: onuremreonur@gmail.com \\ Meral Elci \\ Yalova University, Turkey \\ Email: meral@gyte.edu.tr
}

Doi:10.5296/ ijhrs.v5i2.7441 URL: http://dx.doi.org/10.5296/ ijhrs.v5i2.7441

\begin{abstract}
The purpose of the study is to check if the cost of commuting reduces job satisfaction and lead to withdrawal. A cross-sectional design is implemented by electronic surveys through a snowball sampling $(N=210)$. Regression analysis and SPSS extension called PROCESS is used. Study could not generate enough statistical power to point out a relationship between the time spent during the commute and withdrawal behavior, between the money spent during the commute and withdrawal behavior, between time spent during the commute and job satisfaction. The hypothesized interaction of job satisfaction both on the relationship between the time spent during the commute and withdrawal, and the money spent during the commute and withdrawal behavior are not supported. The results concluded that monetary costs of commuting reduces job satisfaction, job satisfaction mediates the relationship between the time spent during the commute and withdrawal behavior. Job satisfaction also found to mediate the relationship between monetary costs of commuting and withdrawal behavior.
\end{abstract}

Keywords: commuting; withdrawal; counterproductive, satisfaction 


\section{Introduction}

Decentralization of job opportunities and residential areas have altered commuting behaviors, distances, costs and outcomes (Rouwendal, 1999) (Ben-David and Sharabi, 2009). The rise of poly-centric cities and the spread of employers across those cities have complicated travelling to and from work, thus generated organizational consequences (Clark, Huang and Withers, 2003) as it makes individuals worse off, increases stress (Koslowsky, Aizer and Krausz, 1996) and makes people believe they are undercompensated (Stutzer and Frey, 2008). Despite the costs of commuting; Stutzer and Frey (2007) mentioned that travelling longer distances can be tolerated if there are advantages associated with commuting such as better income and more desirable living environment.

Commuting also makes a greater variety of jobs accessible to individuals but at the same time it limits their employment opportunities with jobs closer to them. Commuting can offer superior housing alternatives with lower market values and lower rents as the distance to the center increases (J. van Ommeren, Rietveld and Nijkamp, 1997).

Job dissatisfaction and job mobility are among the several consequences of commuting (Novaco, Stokols and Milanesi, 1990). A study in the United States found that $48 \%$ of working adults reported greater job dissatisfaction due to commuting, $32 \%$ took commuting into consideration upon deciding on their current job, $27 \%$ of the respondents reported that they could perform their duties from home and $15 \%$ reported they would change their job for a shorter commute (Road Wage Survey, 2011). According to Kluger (1998) long distance commuting can easily be associated positively with tardiness, absenteeism and job dissatisfaction. According to Koslowsky (1997); a decrease in performance, increases in job dissatisfaction and organizational withdrawal are can be considered as consequences of the commuting experience.

Any employee weighs the costs and benefits of a particular job opportunity in any given time. In the job search period, the job seeker searches for the jobs within the same city, among the jobs that are close to the residency and jobs that are easy to access every day. As van den Berg and Gorter (1997) stated, commuting cost is an important determinant of job search behavior. As costs increase, the job seeker becomes reluctant to accept faraway jobs, or prefers relatively closer ones even if those jobs offer lower wages.

This reluctance about faraway jobs continues even when the individual actually finds a suitable job opportunity. It is the "stress that does not pay" and it generates the lowest level of positive affect and lowest level of enjoyment throughout the day (Kahneman, Krueger, Schkade, Schwarz, \& Stone, 2004; Kahneman \& Krueger, 2006). In order to endure a long commute, individuals have to derive or expect a form of utility from it.as it is the most disliked activity during the day, even above the work itself (Krueger, Kahneman, Schkade, Schwarz and Stone, 2009). There is a wide set of effects about the trips between home and work that are expected to result in physiologic and psychological responses, lower productivity along with increased absenteeism (Koslowsky, 1997) and lateness (J. N. van Ommeren and Gutiérrez-i-Puigarnau, 2011). 


\section{The Relationship between Commuting, Satisfaction and Withdrawal}

Commuting cost is an important determinant when someone considers his or her willingness to accept a job offer, evaluates the wage offered prior to the job, or even decides to stay in the job. This study puts forward the argument that as the commuting costs increase, employees are more likely to exhibit withdrawal behaviors. Along with the monetary costs of commuting, time also an important part of the commuting costs (J. Van Ommeren and Fosgerau, 2009) and also there is always a tradeoff between wages and costs. According to those arguments, this study hypothesizes as follows:

- Hypothesis 1: Time spent during the commute is positively related to withdrawal behavior.

- Hypothesis 2: Monetary costs of commuting are positively related to withdrawal behavior.

- Hypothesis 3: Time spent during the commute is negatively related to job satisfaction.

- Hypothesis 4: Monetary costs of commuting are negatively related to job satisfaction.

\section{Indirect Effects of Commuting Costs on Withdrawal through Job Satisfaction}

Withdrawal behaviors are the outcomes of the perceptions of injustice, mistreatment, abuse etc. and sometimes even co-workers are the reason for people to avoid the workplace (Hanisch and Hulin, 1991) (Bawa and Jantan, 2005). But among all, job satisfaction is generally accepted as the main reason of employee withdrawal (Robbins and Judge, 2010).

Borrowing the argumentation from the theory of planned behavior (Ajzen, 1991), one can argue that dissatisfied individuals tend to exhibit withdrawal behaviors, hoping to find themselves in a more satisfying status, either by being late, or not showing up for work at all, or by changing workplaces within the same employer and finally by quitting or changing jobs. It is an instrument that helps workers escape from stressors and dissatisfaction in the workplace (Spector et al., 2006).

Costa, Pickup and Martino (1988) found that commuters and non commuters differ significantly in their levels of job satisfaction, because only about $28 \%$ of the commuters were found to be satisfied with their jobs. As proposed in the work of Brooke (1986); the relationship between the predecessors and withdrawal behavior is mediated by job satisfaction and this mediating relationship is pretty much consistent throughout studies. Similarly, this study proposes that the costs of commuting indirectly effect withdrawal behavior through job satisfaction, as job satisfaction being both a mediator and a moderator. Any commuting experience is hypothesized to be prone to generate an effect on withdrawal behavior depending on the individuals level of satisfaction from its job.

- Hypothesis 5: Job satisfaction mediates the relationship between the time spent during the commute and withdrawal. 
- Hypothesis 6: Job satisfaction mediates the relationship between the monetary cost of commuting and withdrawal.

- Hypothesis 7: Job satisfaction moderates the relationship between the time spent during the commute and withdrawal.

- Hypothesis 8: Job satisfaction moderates the relationship between the monetary cost of commuting and withdrawal.

\section{Participants and Procedure}

Data were collected from employees through a snowball sampling procedure in Turkey. Respondents were asked to participate by providing them the survey link through e-mails and they were further asked to invite their professional networks, acquaintances, friends and family to the study. We were able to achieve a diverse sample because we did not limit the profession or industry. As a side effect of the e mail snowballing, a response rate cannot be generated.

A total of 210 working people responded to the study. Majority of the participants were male (79\%), about half of the participants were under the age of $30(55,2 \%)$.

$49 \%$ of the sample were single, $18.1 \%$ of the participants were married with a non-working spouse and $32.9 \%$ of the participants had a working spouse.

Our sample consists of highly educated individuals with an average tenure of 3 years. 21 people (10\%) have at least a high school education, 132 people have at least college degree $(62.9 \%)$ and 57 people have $(27.1 \%)$ post graduate degrees or higher.

All constructs were assessed with validated scales. Survey consists of a job satisfaction scale created by Spector (1985). This scale has proven to be valid and reliable in Turkish. Participants responded using a 5-point Likert scale ranging from 1 (disagree very much) to 5 (agree very much), and the scale displayed high internal consistency for the current sample $(\alpha=0,87)$.

Withdrawal was measured with the items from ste study of Gruys and Sackett (2003). Using a response format ranging from 1 (never) to 5 (always), we asked participants to indicate the frequency with which they behaved as such. A sample item was "Intentionally come to work late". The reliability score for this scale was $\alpha=0,76$.

Money and time spent on commuting were assessed with semantic scales. For the monetary costs, the amount of money spent is asked as a proportion to income with the responses ranging from 1 (too little) to 5 (too much). The information about the time spent during the commute is asked with the response options from 1 (up to 20 minutes) to 5 (100 minutes or more).

\section{Data Analysis}

To test our hypothesis about the positive relationship between the time spent during the commute and withdrawal behavior, we conducted a regression analysis. Analysis resulted a 
very small $\mathrm{R}^{2}\left(\mathrm{R}^{2}=0,011\right)$ with a $p=0,126$. According to our data, our study could not generate enough statistical power to point out a relationship between time spent during the commute and withdrawal behavior. Thus, Hypothesis 1 is not supported.

A regression analysis between monetary cost and withdrawal behavior resulted in a $\mathrm{R}^{2}$ value $\left(\mathrm{R}^{2}=0,002\right)$ and a $p=0,550$. Due to the small $\mathrm{R}^{2}$ value and a non- significant $p$, there is not enough statistical significance to propose that money spent on commuting can affect withdrawal behavior and to support Hypothesis 2.

Regression analysis for the relationship between time spent during the commute and job satisfaction resulted in a $\mathrm{R}^{2}$ value of 0,103 ; thus Hypothesis 3 is not supported. $(p=0,103)$.

The relationship between the monetary cost of commuting and job satisfaction found to be significant at $p=0,019$ with a $\mathrm{R}^{2}$ value of 0,026 . Negative relationship is confirmed in this analysis with a negative value of $\beta$. Monetary costs of commuting was negatively related to job satisfaction, supporting our Hypothesis 4.

In order to test the mediation effect, we applied conditional process analysis by using the PROCESS macro created by Hayes (2013). The analysis resulted in a significant negative indirect effect and supported the Hypothesis 5 (LLCI:-0629 - ULCI:-0,018; 10000 bootstrap samples) that there is an indirect negative effect of time spent on commuting on withdrawal via job satisfaction.

The effect of monetary cost of commuting on withdrawal is found to be mediated by job satisfaction (LLCI:0.0044 - ULCI:0.1795). This result supported the Hypothesis 6.

Analyses to detect the moderating effect of job satisfaction on the relationship between time spent during the commute and withdrawal yielded non significant results (LLCI:-0,413 ULCI:0,4267). Also, no significant relationship is detected between the cost of commuting and withdrawal with the interaction of job satisfaction (LLCI:-0,2758 - ULCI:0,423). Hypothesis 7 and 8 were both not supported.

\section{Discussion}

Our daily life experiences showed us that commuting is almost always a nerve racking routine one has to bear. In scientific sense, it is at the heart of city planning, transportation and housing fields and there is relatively less attention to it from an organizational behavior perspective.

In sum, the present study showed that there is statistically non significant relationship between time spent commuting and withdrawal behavior. There might be a few reasons behind that non significance. Time spent during the commute, is a product of distance, transport mode and infrastructure rather than being a result of a conscious choice made by the commuter. It might be considered as given and that might not interfere with the behaviors toward the job or work. Withdrawal also brings important consequences for people, especially with limited flexibility within their organizations either due to their fixed skills and current investments in their jobs and due to the shortage of other employment opportunities in the market. This can be justified according to (Muchinsky and Morrow, 1980), as they state 
that negative attitudes could not be easily expressed during periods of high unemployment. People tend to resist to their longer commutes to avoid the undesirable unemployment. That explanation seems valid in our sample because the nationwide unemployment levels were relatively high among participants at the time of the study (according to Turkstat (2014) about $10 \%$ nationwide, especially for young people at 19\%; as relatively young labor force constitutes the majority of the sample).

Along with the time spent during the commute, money spent for commuting did not predict withdrawal behavior. Similar to the relationship between time cost and withdrawal; spending more money on commuting is a result of an expensive transportation, long distances and lack of other alternatives. An expensive commute can easily be seen as an outcome of overall price level and/or high costs rather than seeking a retaliation towards the work or the job. Expensive gas, high costs of public transportation, inevitable long distances and a tight labor market, can easily shift the focus away from the organization.

Concerning the non-significant relationship between time spent during the commute and job satisfaction, one might argue that this finding is parallel to the non-significant relationship between time spent commuting and withdrawal. The waste of time is not considered as a part of the job itself, but is instead seen as a result of other factors like traffic congestion etc. and it is given in the work settings. Sonnentag and Frese (2013) provides examples of studies that has weak and non significant relationships with absenteeism, even negative relationships among stressors and absenteeism. A mediating mechanism through strain or the common variance between the strain and the stressor might be the cause of such outcome between the stressor and withdrawal.

Analysis of the hypothesized indirect relationship between withdrawal and time spent commuting via job satisfaction yielded a suppression effect. Direct and indirect effects of the time costs of commuting, cancels each other out (MacKinnon, Fairchild and Fritz, 2007; MacKinnon, Krull and Lockwood, 2000). This would indicate the increased withdrawal due to the increase in commuting time is outweighed by the decreases in withdrawal due to the level of satisfaction. Job satisfaction is a dominant and well established predictor of withdrawal in comparison to the time costs of commuting, thus cancelling effects of commuting time and makes the indirect effect negative. Long commuters will experience less withdrawal if they have high levels of satisfaction with their work. Even though their commute is long, they will be consent with that and resort to withdrawal less, keeping the redeeming features of the jobs in mind. It is reasonable to infer that people with a satisfying job can acquiesce long commutes.

Moderating effect of job satisfaction is also tested both for time and money spent during the commute on withdrawal. There is no significant moderating effect has been found for our sample. The result is not surprising given the results about the direct effects and relative difficulty in finding moderator effects (McClelland and Judd, 1993) (Aguinis, 1995) (Champoux and Peters, 1987).

It should also be considered that people actually can utilize their commute. Even further, according to Redmond and Mokhtarian (2001), J. Van Ommeren (1998), Lyons and 


\section{Mll Macrothink}

International Journal of Human Resource Studies

ISSN 2162-3058

2015, Vol. 5, No. 2

Chatterjee (2008), Ory et al. (2004) people need an optimum commuting time rather than zero commuting and individuals are willing to travel longer than their actual commute. Consistent with that finding, commuting time is not always a waste of time, it can be something that the commuter wants just for travel purposes, to catch up with daily reading, to conduct phone calls or for things that they do not want to allocate their time otherwise. This is also supported by Ory et al. (2004) with the concept of "subjective mobility" explaining the individual differences in evaluating the commute. Individuals have different views about a bad a commute, according to their level of tolerance for stressors and their utilization of the commute or their experiences during the commute.

Physical or mental, any commute is an expenditure of effort and other resources for the individual. It is not only time, but the way its allocation and individual differences are important to interpret the outcomes. van Hooff (2013) reports that psychological detachment from work during the commute is important for many commuters. Commute from work can be the time for individual to relax and unwind from work. It is a transition between work and home, and helps people change their mood and it provides a transmission between roles. Depending on the pleasantness of the commute, it can be considered a form of recovery. According to Gatersleben and Uzzell (2007), this might be the only part of the day when individuals have the chance to dedicate to themselves.

Conditions that shape the working life can also be used to explain the results. As Berry, Leelchook and Clark (2012) suggested in their study; organizational norms can be very important on the salience of withdrawal behaviors. There are many organizations with strict measures against any form of counterproductive behavior, whereas some of them might appreciate more flexibility in their work structure. Among our sample, only $13.8 \%$ of the participants reported unconventional work schedules, meaning that the majority of the participants either work in day shifts as white or blue collar workers. These forms of working often have minimum degree of flexibility, moreover those work sites are often subject to attendance controls, even surveillance to some degree.

The effect of job security on work behaviors are reported by Reisel, Probst, Chia, Maloles and König (2010). This can be regarded as an important antecedent of counterproductive behavior in various direct and indirect ways. Another study by Staufenbiel and König (2010) reports such results; arguing that challenge and hindrance effects of job insecurity as a stressor have simultaneous effects on withdrawal. Probst, Stewart, Gruys and Tierney (2007) also reported that high levels of job insecurity leads to fewer counterproductive behavior at work because it puts employees at jeopardy. As people are forced by economical factors to remain the organization, they may resort to other forms of manifestations of their dissatisfaction, rather than physical withdrawal.

\section{Limitations of the current study}

There are several limitations to this study. The amount of the spent during the commute and monetary costs of the commute are measured by asking participants how much they spend on both, since keeping time logs or calculating exact costs of commuting was not practical in the scope of this study. 
In this study, we used cross-sectional design and measured all variables as self reports and that might have lead to common method bias. Also operationalization of withdrawal by using company reports or behavioral frequencies or a combination of those methods can be employed as a superior method, instead of using a self report measure. Self report method is chosen because of its high correlation with record based data (Shapira-Lishchinsky and Rosenblatt, 2008), to provide anonymity as advised by Fox, Spector and Miles (2001). As stated in Johns (2003), organizations rarely keep adequate records for withdrawal and access to these records are often not permitted.

As a consequence of the nature of the constructs measured, and although the efforts to achieve unanimity and confidentiality for the participants, dissatisfaction and withdrawal might be a victim of underreporting. According to Berry, Carpenter and Barratt (2012) there are skeptical views on self reports of counter-productivity. Socially undesired behaviors might be subject to socially desirable responses, especially in self reporting even though there are not any risks for the participant (Randall and Fernandes, 1991).

The demographics of the study turned out to be young, relatively new at the working life and single. These people can show varying degrees of vulnerability to unemployment and job insecurity. Young people might be more resistant to dissatisfaction and withdrawal more willing to bear the higher costs and burdens of commuting.

\section{Practical Implications and Directions for Further Research}

\section{Directions For Future Research}

Further studies should take concepts like stress and burnout into consideration upon investigating relationships that are hypothesized to be affected by commuting. Job market and city structure is also important and should be taken into account before designing studies.

Job security and unemployment might be more important than this study already acknowledged, and those constructs need special attention in the studies with any form of counterproductive behavior. High unemployment and tight job market curbs the tendency to withdraw from work and brings less flexibility to employers. Future studies should find ways to incorporate unemployment and job market conditions into their analysis.

Job commitment and job engagement are also among the major determinants of withdrawal, and those should be investigated as outcomes of commuting. These constructs might also be possible mediators or moderators between commuting and various organizational outcomes.

Along with job satisfaction, life satisfaction is also important as it is also affected by commuting experiences. Social interactions, family life and work-life balance are the ones that might suffer the most from an unpleasant commute. Studies incorporating these relationships will be drawing a better picture of commuting in life.

\section{Implications for Practice}

Employers should implement creative and progressive strategies against possible negative effects of commuting regardless of the current situation in order to avoid long term stressor 
effects and productivity concerns. Flexible working hours and compressed work weeks would help workers to allocate their productive time to work. Commuting related problems should be a mutual concern for both parties rather than leaving the burden to the commuter.

Some employers actually put efforts into reducing the burden of commuting. The majority of the blue collar workers among our sample commute with the company provided shuttles and this stands for an important fringe benefit. Further study might include such benefits into the design and investigate the possible effects of those benefits to outcomes.

Results also show that there is no reason for employers to put residential neighborhood limitation in the job advertisements. Employers are sometimes concerned about the applicants' distance from the workplace and tend to discriminate the applicants whom they think will have a difficult commute if they are recruited. Results from this study have no support for this view and selecting shorter commuters will only limit the applicant pool and lead to a worse selection.

\section{Conclusion}

Overall, the results from this study are important because they demonstrate the effects of the money spent on commuting and monetary costs are not enough to rely on upon explaining withdrawal behaviors. Time and monetary costs are seen as elements of working life and employee has almost no discretion on the determinants. Monetary costs are dependent on the economic indicators and time spent during the commute is an outcome of infrastructure, leaving no room for the employee to adjust the behavior for a better outcome.

Commuting takes time and money, and do not use it in a productive way. In natural flow of life, it is considered one of the worst things to do in a day. A study by Krueger et al., (2009) puts commuting among the most disliked activities. As mentioned before, even working itself is not as bad as going to work.

It is important to note that commuters are all trapped with their commuting status. There are no better options for them to improve their commute and they cannot completely get rid of it. The majority of the possible improvements are beyond the their discretion and the ones that they can adjust might need long term planning. Reducing the cost of the commute is almost always impossible, given the costs associated with the commute are often exogenous.

Avoiding a lengthy commute is possible if an employer changes residence or workplace. Either one is a major life changing event, require intensive planning and takes time to implement. But the effects of a lengthy commute are immediate. If an individual suffering from a long commute plans to switch jobs, he or she will probably be faced with more dramatic situations especially in job markets with higher unemployment levels. Even in the markets with lower unemployment, fixed investments toward the job will be an important factor upon deciding to switch jobs or stay.

\section{References}

Aguinis, H. (1995). Statistical power with moderated multiple regression in management research. Journal of Management. 
Ajzen, I. (1991). The Theory of Planned Behavior. Organizational Behavior and Human Decision Processes, 50, 179-211.

Bawa, M. A., \& Jantan, M. (2005). Human resource practices as determinants of employee turnover : an empirical investigation. Asian Academy of Management Journal, 10(2), 69-80.

Ben-David, N., \& Sharabi, M. (2009). Commuting and Its Effect on Work Decisions. International Journal of Economic Perspectives, 3(3), 183-187.

Berry, C. M., Carpenter, N. C., \& Barratt, C. L. (2012). Do other-reports of counterproductive work behavior provide an incremental contribution over self-reports? A meta-analytic comparison. The Journal of Applied Psychology, 97(3), 613-36.

Berry, C. M., Leelchook, A. M., \& Clark, M. A. (2012). A meta analysis of the interrelationships between employee lateness, absenteeism, and turnover: Implications for models of withdrawal behavior. Journal of Organizational Behavior, 33(2012), 678-699.

Brooke, P. P. (1986). Beyond the Steers and Rhodes model of employee attendance. Academy of Management Review, 11(2), 345-61.

Champoux, J., \& Peters, W. (1987). Form, effect size and power in moderated regression analysis. Journal of Occupational Psychology, (November 1981), 243-255.

Clark, W. A. V, Huang, Y., \& Withers, S. (2003). Does commuting distance matter? Commuting tolerance and residential change. Regional Science and Urban Economics, 33, 199-221.

Costa, G., Pickup, L., \& Martino, V. Di. (1988). Commuting - a further stress factor for working people: evidence from the European Community. International Archives of Occupational and Environmental Health, 60, 377-385.

Fox, S., Spector, P. E., \& Miles, D. (2001). Counterproductive Work Behavior (CWB) in Response to Job Stressors and Organizational Justice: Some Mediator and Moderator Tests for Autonomy and Emotions. Journal of Vocational Behavior, 59(3), 291-309.

Gatersleben, B., \& Uzzell, D. (2007). Affective Appraisals of the Daily Commute: Comparing Perceptions of Drivers, Cyclists, Walkers, and Users of Public Transport. Environment and Behavior, 39(3), 416-431.

Gruys, M. L., \& Sackett, P. R. (2003). Investigating the Dimensionality of Counterproductive Work Behavior. International Journal of Selection and Assessment, 11(1), 30-42.

Hanisch, K. A., \& Hulin, C. L. (1991). General attitudes and organizational withdrawal: An evaluation of a causal model. Journal of Vocational Behavior, 39(1), 110-128.

Hayes, A. F. (2013). Introduction to Mediation, Moderation, and Conditional Process Analysis: A Regression-based Approach. New York: Guilford Press.

Johns, G. (2003). How methodological diversity has improved our understanding of absenteeism from work. Human Resource Management Review, 13, 157-184. 
Kahneman, D., \& Krueger, A. B. (2006). Developments in the Measurement of Subjective Well-Being. Journal of Economic Perspectives.

Kahneman, D., Krueger, A. B., Schkade, D. a, Schwarz, N., \& Stone, A. a. (2004). A survey method for characterizing daily life experience: the day reconstruction method. Science (New York, N.Y.), 306(2004), 1776-1780.

Kluger, A. (1998). Commute variability and strain. Journal of Organizational Behavior, 19(May 1996), 147-165.

Koslowsky, M. (1997). Commuting Stress: Problems of Definition and Variable Identification. Applied Psychology, 46(2), 153-174.

Koslowsky, M., Aizer, A., \& Krausz, M. (1996). Stressor and Personal Variables in the Commuting Experience. International Journal of Manpower, 17(3), 4 - 14.

Krueger, A. B., Kahneman, D., Schkade, D., Schwarz, N., \& Stone, A. A. (2009). National time accounting: The currency of life. In Measuring the Subjective Well-Being of Nations: National Accounts of Time Use and Well Being (Vol. I, pp. 1-84).

Lyons, G., \& Chatterjee, K. (2008). A Human Perspective on the Daily Commute : Costs , Benefits and Trade-offs. Transport Reviews, 28(January 2012), 37-41.

MacKinnon, D. P., Fairchild, A. J., \& Fritz, M. S. (2007). Mediation Analysis. Annual Review of Psychology, 58(1), 593-614.

MacKinnon, D. P., Krull, J. L., \& Lockwood, C. M. (2000). Equivalence of the mediation, confounding and suppression effect. Prevention Science: The Official Journal of the Society for Prevention Research, 1(4), 173-81.

McClelland, G. H., \& Judd, C. M. (1993). Statistical difficulties of detecting interactions and moderator effects. Psychological Bulletin, 114(2), 376-90.

Muchinsky, P., \& Morrow, P. (1980). A multidisciplinary model of voluntary employee turnover. Journal of Vocational Behavior, 290, 263-290.

No Title. (2014). Turkish Statistics Institute. Retrieved March 01, 2014, from http://www.turkstat.gov.tr/UstMenu.do?metod=temelist

Novaco, R. W., Stokols, D., \& Milanesi, L. (1990). Objective and subjective dimensions of travel impedance as determinants of commuting stress. American Journal of Community Psychology, 18(30), 231-257.

Ommeren, J. Van. (1998). On-the-job search behavior: the importance of commuting time. Land Economics, 74(4), 526-540.

Ory, D. T., Mokhtarian, P. L., Redmond, L. S., Salomon, I., Collantes, G. O., \& Choo, S. (2004). When is Commuting Desirable to the Individual? Growth and Change, 35(3), 334-359.

Probst, T. M., Stewart, S. M., Gruys, M. L., \& Tierney, B. W. (2007). Productivity, 
counterproductivity and creativity: The ups and downs of job insecurity. Journal of Occupational and Organizational Psychology, 80(3), 479-497.

Randall, D. M., \& Fernandes, M. F. (1991). The social desirability response bias in ethics research. Journal of Business Ethics, 10(11), 805-817.

Redmond, L. S., \& Mokhtarian, P. L. (2001). The positive utility of the commute : modeling ideal commute time and relative desired commute amount, 179-205.

Reisel, W. D., Probst, T. M., Chia, S.-L., Maloles, C. M., \& König, C. J. (2010). The Effects of Job Insecurity on Job Satisfaction, Organizational Citizenship Behavior, Deviant Behavior, and Negative Emotions of Employees. International Studies of Management and Organization, 40(1), 74-91.

Road Wage Survey. (2011). Retrieved from http://www.kronos.com/pr/road-wage-survey.aspx

Robbins, S. P., \& Judge, T. A. (2010). Essentials of organizational behavior (10th ed.). Upper Saddle River, NJ.: Pearson Prentice Hall.

Rouwendal, J. (1999). Spatial job search and commuting distances. Regional Science and Urban Economics, 29(4), 491-517.

Shapira-Lishchinsky, O., \& Rosenblatt, Z. (2008). Perceptions of Organizational Ethics as Predictors of Work Absence: A Test of Alternative Absence Measures. Journal of Business Ethics, 88(4), 717-734.

Sonnentag, S., \& Frese, M. (2013). Stress in Organizations. In Handbook of Psychology (pp. 560-592).

Spector, P. (1985). Measurement of human service staff satisfaction: Development of the Job Satisfaction Survey. American Journal of Community Psychology, 13(6).

Spector, P., Fox, S., Penney, L. M., Bruursema, K., Goh, A., \& Kessler, S. (2006). The dimensionality of counterproductivity: Are all counterproductive behaviors created equal? Journal of Vocational Behavior, 68(3), 446-460.

Staufenbiel, T., \& König, C. J. (2010). A model for the effects of job insecurity on performance, turnover intention, and absenteeism. Journal of Occupational and Organizational Psychology, 83(1), 101-117.

Stutzer, A., \& Frey, B. S. (2007). Commuting and Life Satisfaction in Germany. Informationen Zur Raumentwicklung, 2, 1-11.

Stutzer, A., \& Frey, B. S. (2008). Stress that Doesn't Pay: The Commuting Paradox*. Scandinavian Journal of Economics, 110(2), 339-366.

Van den Berg, G. J., \& Gorter, C. (1997). Job Search and Commuting Time. Journal of Business \& Economic Statistics, 15(2), 269.

Van Hooff, M. L. M. (2013). The Daily Commute from Work to Home: Examining Employees' Experiences in Relation to Their Recovery Status. Stress and Health : Journal of 


\section{Macrothink \\ International Journal of Human Resource Studies \\ ISSN 2162-3058 2015, Vol. 5, No. 2}

the International Society for the Investigation of Stress.

Van Ommeren, J., \& Fosgerau, M. (2009). Workers' marginal costs of commuting. Journal of Urban Economics, 65(1), 38-47.

Van Ommeren, J. N., \& Gutiérrez-i-Puigarnau, E. (2011). Are workers with a long commute less productive? An empirical analysis of absenteeism. Regional Science and Urban Economics, 41(1), 1-8.

Van Ommeren, J., Rietveld, P., \& Nijkamp, P. (1997). Commuting: In Search of Jobs and Residences. Journal of Urban Economics, 42(3), 402-421. 